\title{
Intestinal Apolipoprotein Al Gene Transcription Is Regulated by Multiple Distinct DNA Elements and Is Synergistically Activated by the Orphan Nuclear Receptor, Hepatocyte Nuclear Factor 4
}

\author{
Geoffrey S. Ginsburg, ${ }^{\star \ddagger}$ Josef Ozer, ${ }^{\S}$ and Sotirios K. Karathanasis ${ }^{\star \$}$ \\ * Laboratory of Molecular and Cellular Cardiology, Department of Cardiology, Children’s Hospital and ${ }^{\ddagger}$ Department of Medicine, \\ Beth Israel Hospital, Harvard Medical School, Boston, Massachusetts 02115; and ${ }^{\S}$ Department of Cardiovascular Molecular Biology, \\ Lederle Laboratories, American Cyanamid Co., Pearl River, New York 10965
}

\begin{abstract}
We have used apolipoprotein genes to investigate the signal transduction mechanisms involved in the control of intestinal specific gene expression. The human apoAI, apoCIII, and apoAIV genes are tandemly organized within a 15-kb DNA segment and are expressed predominantly in the liver and intestine. Transient transfection of various human apoAI gene plasmid constructs into human hepatoma (HepG2) and colon carcinoma (Caco-2) cells showed that apoAI gene transcription is under the control of two separate and distinct cell-specific promoters. The region between nucleotides -192 and -41 is essential for expression in HepG2 cells, whereas the region from -595 to -192 is essential for expression in Caco-2 cells. A third $0.6 \mathrm{~kb}$ DNA fragment in the apoCIII gene promoter region, $\sim 5 \mathrm{~kb}$ downstream from the human apoAI gene, enhances transcription mediated by either of these two tissue-specific apoAI promoters. In Caco-2 cells, expression of the apoAI gene and activation by the distal enhancer required the presence of a nuclear hormone receptor response element (NHRRE) located in the -214 to -192 apoAI promoter region. Overexpression of the orphan receptor hepatocyte nuclear factor 4 (HNF-4), which binds to the NHRRE, dramatically stimulates apoAI gene expression in Caco-2 cells but not in HepG2 cells. Maximal stimulation of transcription by HNF-4 in Caco- 2 cells required the presence of both the intestinal specific promoter, the NHRRE, and distal enhancer elements. Transactivation by HNF-4 thus appears to result from functional synergy between the NHRRE binding HNF-4 and distal DNA elements containing intestinal-specific DNA binding activities. The apoAI gene provides a model system to define the mechanism(s) governing intestinal cell specific gene regulation and the role of nuclear hormone receptors in the establishment and regulation of enterocytic gene transcription. (J. Clin. Invest. 1995. 96:528538.) Key words: gene transcription - transcriptional regu-
\end{abstract}

Address correspondence to Geoffrey S. Ginsburg, M.D., Ph.D., Cardiovascular Division, Beth Israel Hospital, 330 Brookline Avenue, Boston, MA 02215. Phone: 617-667-4110; FAX: 617-667-4833; E-mail: Ginsburg@phenix.tch.harvard.edu.

Received for publication 22 March 1994 and accepted in revised form 14 March 1995.

J. Clin. Invest.

(C) The American Society for Clinical Investigation, Inc. 0021-9738/95/07/0528/11 \$2.00

Volume 96, July 1995, 528-538 lation • nuclear hormone receptors • apolipoprotein genes • intestine

\section{Introduction}

Surprisingly little is known about DNA regions or factors controlling intestinal expression of apolipoprotein or other genes. While several studies have shown that $c i s$-acting DNA elements are responsible for directing intestinal cell-specific transcription of certain genes as well as their developmental and spatial patterns of expression (1-7), few have precisely defined these elements and their cognate transcription proteins (8). For several years, we have used apolipoprotein genes as a model to understand the tissue-specific mechanisms controlling gene expression in hepatocytes and enterocytes $(9-14)$. In this report we describe distinct DNA regions required for the expression of the apoAI gene in liver and intestine. We further show that the orphan nuclear hormone receptor, hepatocyte nuclear factor 4 (HNF-4), ${ }^{1}$ when overexpressed, induces high levels of apoAI gene expression in intestinal but not liver cells.

ApoAI is a lipid binding protein involved in the transport of cholesterol and other lipids in the plasma. ApoAI is the major protein constituent of HDL, which are thought to play an important role in atherosclerosis prevention (reviewed in reference 15). In mammals, the gene encoding apoAI is expressed predominantly in liver and intestine, and it is regulated by various developmental, hormonal, and dietary factors and by various environmental and physiological stimuli $(13,15$, and references therein). Although there has been progress in defining the cis- and trans-acting factors involved in establishment and regulation of hepatocyte specific expression of the apoAI gene $(9-13,16-18)$, little is known regarding factors regulating its enterocyte specific expression $(9,19,20)$.

The apoAI, apoCIII, and apoAIV genes are closely linked and tandemly organized within a 15-kb DNA segment in mammalian and avian genomes (21-24). The human apoAI and apoCIII genes are separated by $\sim 2.9 \mathrm{~kb}$ and are transcribed convergently from opposite DNA strands. The apoAIV gene is located $\sim 7.5 \mathrm{~kb}$ upstream of the apoCIII gene and is transcribed from the same DNA strand as the apoAI gene (21). The DNA regions from -222 to -110 and $-1,469$ to -192 upstream of the apoAI gene transcriptional start site $(+1)$ are necessary and sufficient for expression of the apoAI gene in human hepatoma (HepG2) and human colon carcinoma (Caco2) cells, respectively (9).

1. Abbreviations used in this paper: CAT, chloramphenicol acetyl transferase; EMSA, electrophoretic mobility shift assays; HNF-4, hepatocyte nuclear factor 4; LCR, locus control region; NHRRE, nuclear hormone receptor response element. 
The importance of the -222 to -110 element in the liverspecific expression of the apoAI gene has been confirmed in transgenic mice (19). However, these studies did not clarify the role of the $-1,469$ to -192 element in intestinal specific expression. Transgenic mice containing the human $-1,469$ to -192 apoAI promoter region do not express apoAI in the intestine $(19,20)$. However, when the transgene contains, in addition, a portion of the distal apoCIII/apoAIV intergenic region, from $-1,411$ to -194 upstream of the apoCIII gene, the mice express apoAI in the intestine (24-26).

In this report, the expression of human apoAI gene was studied in Caco-2 and HepG2 cells using constructs that either contain or lack a 7-kb DNA segment that spans the apoCIIII ApoAIV intergenic region. This DNA segment enhanced expression of the apoAI gene in both cell types. The -192 to -41 apoAI promoter domain was essential for this enhancement in HepG2 but not in Caco-2 cells, and the -595 to -192 apoAI promoter domain was essential for enhancement in Caco-2 but not in HepG2 cells. Deletion mapping analysis revealed that the activity of this distal enhancer colocalized with the apoCIII promoter region $(-770$ to -194$)$. Further, a nuclear hormone receptor response element (NHRRE) $(11-13)$ in the apoAI promoter region (nucleotides -214 to -192 ) was essential for expression of the apoAI gene in Caco-2 but not in HepG2 cells. Binding of HNF-4 (27) to the NHRRE in the context of both the native apoAI gene promoter and the apoCIII/apoAIV intergenic region further enhanced apoAI gene expression in Caco-2 but not in HepG2 cells. Thus, overexpression of HNF-4 permits functional synergy to occur among several DNA elements to induce high levels of apoAI gene transcription.

These results indicate that transcription of the apoAI gene is regulated by cis-elements both immediately upstream of this gene and in the apoCIII gene promoter region and that HNF4 , while present in both liver and intestinal cells, activates the apoAI gene promoter and its distal enhancer exclusively in intestinal cells. The apoAI gene thus provides a useful system in order to define the mechanisms governing intestinal cell specific gene regulation and the role of nuclear hormone receptors and other proteins in establishment and regulation of enterocytic gene transcription.

\section{Methods}

Plasmid constructions and propagation. Various plasmids were constructed and purified as described $(13,28)$. The apoAI/chloramphenicol acetyltransferase (cat) gene fusion constructs -2500AI.CAT, -1469AI.CAT, -366AI.CAT, -256AI.CAT, -192AI.CAT, -41AI.CAT, $-2500[\Delta-192 /-42]$ AI.CAT, and $-256[\Delta-192 /-42]-$ AI.CAT have been described previously $(9,10)$. To construct $-1469[\Delta-192 /-42]$ AI.CAT, a $1.1-\mathrm{kb}$ Ncol fragment (from the $-2500[\Delta-192 /-42]$ AI.CAT construct's NcoI site at -300 in the apoAI gene to the NcoI site in the cat gene) was used to replace the corresponding fragment in -1469AI.CAT. To construct $-595[\Delta-192]$ -42]AI.CAT, a $0.54 \mathrm{~kb}$ MboI-KpnI fragment (from the $-2500[\Delta-192 /-42]$ AI.CAT construct's MboI site at -595 to the KpnI site at +96 in the apoAI gene) was used to replace the -41AI.CAT construct's $0.13 \mathrm{~kb}$ BamHI-KpnI fragment extending from -41 to the $\mathrm{KpnI}$ site at nucleotide position +96 within the apoAI gene. To construct -595AI.CAT, a 1.25-kb NcoI fragment (from the -366AI.CAT construct's NcoI site at -300 of the apoAI gene to the NcoI site within the cat gene) was used to replace the corresponding fragment in the construct $-595[\Delta-192 /-42]$ AI.CAT. To construct -490AI.CAT, a 0.56kb StuI fragment (from the -1469AI.CAT construct's StuI site at -490 of the apoAI gene to the StuI site at +73 within the apoAI gene) was used to replace the $-256[\Delta-192 /-42]$ AI.CAT construct's SmaI-StuI fragment, extending from -256 to the StuI site at +73 within the apoAI gene. To construct $-490[\Delta-192 /-42]$ AI.CAT, a $0.41 \mathrm{~kb}$ StuI fragment (from the $-595[\Delta-192 /-42]$ AI.CAT construct's StuI sites at -490 and +73 of the apoAI gene) was used to replace the $-256[\Delta-192 /-42]$ AI.CAT construct's SmaI-StuI fragment described above. To construct $-1469[\Delta-238 /-42]$ AI.CAT, the -1469 AI.CAT construct's the -238 to -42 PstI fragment from the apoAI gene (9) was excised, and the construct was religated. Finally, -595AmAI.CAT was made by PCR: the single stranded Amut primers (mutated bases indicated in bold), $5^{\prime}$-CACTGAACCCGGGACCCCTGCCCT- $3^{\prime}$ and 5'-AGGGCAGGGGTCCCGGGTTCAGTG-3' were synthesized and used with the primers flanking the -595AI.CAT plasmid as template to generate two DNA fragments from -595 to -192 and -214 to +397 . These fragments were then melted, and extended with Taq polymerase (Boehringer Mannheim Corp., Indianapolis, IN) to give the -595 to +397 DNA fragment with mutated site A. This fragment was used as template with the flanking primers and subcloned into pUC19.CAT. The presence of the mutated bases was verified by sequencing.

Constructs containing the 7-kb apoCIII/apoAIV domain were made as follows: a 7-kb BamHI fragment, which spans the domain between the human apoCIII and apoAIV genes, including some their coding regions (Fig. 1) was isolated from the genomic clone $\lambda a p o A I-8$ (21) and cloned into constructs -2500AI.CAT and -41AI.CAT at the BamHI site at the $3^{\prime}$ end of the cat gene, thereby generating the constructs -2500AI.CAT[CIII/AIV] and -41AI.CAT[CIII/AIV], respectively. To produce the remaining constructs containing the 7-kb apoCIII/apoAIV domain (Fig. 2), a 2.9-kb HindIII fragment, from the HindIII sites at -2500 and +397 of the apoAI gene in the construct -2500AI.CAT[CIII/AIV], was excised and replaced by a different HindIII fragment, each corresponding to a different new construct. These HindIII fragments were isolated from the constructs -1469AI.CAT, -595AI.CAT, -595AmAI.CAT, -490AI.CAT, -366AI.CAT, -256AI.CAT, -192AI.CAT, -1469[ $\Delta-192 /-42]$ AI.CAT, $-1469[\Delta-238$ / -42]AI.CAT, -595[ $\Delta-192 /-42]$ AI.CAT, and -490[ $\Delta-192 /-42]$ AI.CAT and were used to generate the constructs - 1469AI.CAT[CIII/ AIV], -595AI.CAT[CIII/AIV], -595AmAI.CAT [CIII/AIV], -490AI.CAT[CIII/AIV], -366AI.CAT[CIII/AIV], -256AI.CAT[CIII/ AIV], -192AI.CAT[CIII/AIV], -1469[ $\Delta-192 /-42]$ AI.CAT [CIII/ AIV], -1469[ $\Delta-238 /-42]$ AI.CAT[CIII/AIV], -595[ $\Delta-192 /-42$ ]AI.CAT [CIII/AIV], and -490[ $\Delta-192 /-42$ ]AI.CAT [CIII/AIV], respectively. The double-stranded oligonucleotides encompassing the apoCIII C3P ( -92 to -56$)(29), \mathrm{NF} \kappa \mathrm{B}(-168$ to -144$)(14)$, and I $(-770$ to -722$)(30)$, cis-elements were cloned into the $-2500 \mathrm{AI}$.CAT construct's unique BamHI site, adjacent to the $3^{\prime}$ end of the cat gene, to generate the constructs -2500AI.CAT [CIII:C3P], -2500AI.CAT [CIII:NF $\kappa$ B], and -2500AI.CAT [CIII:I], respectively. Taq polymerase was used to PCR amplify apoCIII gene fragments from -1411 to $-194,-770$ to $-194,-168$ to +783 , and -92 to +783 , and these fragments were cloned into the $-2500 \mathrm{AI}$.CAT construct's unique BamHI site to generate the constructs -2500AI.CAT [CIII: $-1411 /-194$ ], -2500AI.CAT [CIII:-770/-194], -2500AI.CAT [CIII: $-168 /+783]$, and -2500 AI.CAT [CIII:-92/+783], respectively. All constructs were verified by restriction mapping analysis and DNA sequencing of cloning junction regions. The vectors $p M T 2-H N F$ 4, $p M T 2-A R P-1$, and $p M T 2-E a r 3 / C O U P-T F$, which express HNF-4, ARP-1, and Ear3/COUP-TF, respectively, in addition to the control vector $P M T 2-U T$ have been described previously (14).

Oligonucleotides. Oligonucleotides were synthesized on a DNA synthesizer (model 8600; Biosearch, San Rafael, CA), deblocked at $55^{\circ} \mathrm{C}$, and purified by PAGE (28). Complementary oligonucleotides, which span portions of the apoAI gene promoter, all contain GATC overhangs at the $5^{\prime}$ end, were annealed, and used for either cloning or for electrophoretic mobility shift assays (EMSA).

Cell culture, transfections, and CAT assays. Plasmid DNAs were prepared and transfected into cultured cells by the calcium phosphate coprecipitation method (31). All cultured cells were maintained in DME 
(Gibco Laboratories, Grand Island, NY) and supplemented with $10 \%$ FCS (Sigma Immunochemicals, St. Louis, MO) and penicillin and streptomycin at $37^{\circ} \mathrm{C}$ in $5 \% \mathrm{CO}_{2}$. Human hepatoma (HepG2) cells were seeded at $2 \times 10^{6}$ cells $/ 100$-mm dish, colon carcinoma (Caco-2) cells at $2.5 \times 10^{6}$ cells $/ 100 \mathrm{~mm}$ dish, and HeLa cells at $10^{6}$ cells $/ 100-\mathrm{mm}$ dish $24 \mathrm{~h}$ before transfection. To correct for variation in DNA uptake by the cells, $5 \mu \mathrm{g}$ of the plasmid pRSV- $\beta$-gal (32) were cotransfected with each test construct. Protein extracts from transfected cells were made by three cycles of freeze-thaw (9), and the CAT and $\beta$-galactosidase ( $\beta$-gal) enzyme activities of the cell extracts were assayed as described previously (9). In each experiment, the CAT enzymatic activity was normalized relative to that of the $\beta$-gal activity (9). For the series of transfection experiments comparing activities of plasmid constructs either including or excluding the 7-kb apoCIII/apoAIV domain, equimolar amounts of test plasmids corresponding to $25 \mu \mathrm{g}$ ( $2.65 \mathrm{fmol})$ of $-2500 \mathrm{AI}$.CAT [CIII/AIV] were used. pUC19 vector DNA was used to maintain experimental DNA concentration at $25 \mu \mathrm{g}$ when lower molecular weight plasmids were transfected.

Nuclear extracts. Caco-2 and HepG2 cell nuclear extracts were prepared from 20 confluent $150-\mathrm{mm}$ dishes as described in reference 33, except that buffers $A$ and $C$ were supplemented with $1 \mathrm{mM} \mathrm{DTT}$, $1 \mathrm{mM}$ PMSF, and $1 \mathrm{mg} / \mathrm{ml}$ of both pepstatin A and leupeptin (Sigma Immunochemicals). Additionally, buffer $\mathrm{C}$ contained $\mathrm{NaCl}$ at a final concentration of $0.5 \mathrm{M}$, and buffer $\mathrm{D}$ was replaced by a similar buffer, buffer G ( $20 \mathrm{mM}$ Hepes, pH 7.8, $0.1 \mathrm{M} \mathrm{KCl}, 0.2 \mathrm{mM}$ EDTA, $1 \mathrm{mM}$ DTT, $1 \mathrm{mM}$ PMSF, 20\% glycerol). Aliquots of nuclear extracts were snap frozen on dry ice and stored in liquid nitrogen. The protein concentration of extracts was determined by the Lowry assay (34) and was from 3 to $8 \mathrm{mg} / \mathrm{ml}$.

Whole cell extracts. To make whole cell extracts, Cos-1 cells, maintained in DME plus $10 \%$ heat-inactivated $\left(55^{\circ} \mathrm{C}, 1 \mathrm{~h}\right) \mathrm{FCS}$, were transfected with $p M T 2-A R P-1, p M T 2-E A R-3 / C O U P-T F$, or $p M T 2$ $H N F-4$ by the DEAE-dextran procedure as described (35). After $48 \mathrm{~h}$, the cells were harvested and resuspended in buffer G. Cell extracts were produced by three freeze-thaw cycles and stored at $-70^{\circ} \mathrm{C}$.

DNase I protection assays. DNase I protection assays were performed by using the DNA fragments spanning the -256 to -80 (10) and -595 to -256 regions of the apoAI gene as probes. These fragments were labeled with ${ }^{32} \mathrm{P}$ at their $5^{\prime}$ ends of either the coding (sense) or noncoding (antisense) strands as follows. Labeling the -256 to -80 fragment was previously described (10). To label the PCR generated -595 to -256 fragment, it was digested with $\mathrm{MboI}$ and cloned into the BamHI site of the $p U C 19$. The resulting construct was digested with either HindIII or EcoRI site in the polylinker region, dephosphorylated and labeled as above and then digested with EcoRI or HindIII to give labeled sense and antisense strands, respectively. The resulting fragments were isolated by PAGE and electroeluted from DEAE filter strips (NA45, Schleicher and Schuell, Inc., Keene, NH). DNase I experiments were performed as described previously (10)

EMSA. Caco-2 cell nuclear extracts or ARP-1, EAR-3/COUP-TF, or HNF-4 proteins produced from COS-1 cell extracts were incubated with indicated ${ }^{32} \mathrm{P}$-labeled double-stranded oligo probes and run on native PAGE as previously described (10). For antibody EMSA experiments, a 1:10 dilution of antiserum to HNF-4 (27) or antiserum to COUP-TF proteins (36) were added to the mixtures before incubation with the probe for $15 \mathrm{~min}$ at $4^{\circ} \mathrm{C}$.

\section{Results}

A 7-kb DNA fragment spanning the ApoCIII/ApoAIV intergenic region enhances ApoAI gene transcription in liver and intestinal cells. A 2.5-kb DNA segment, located immediately upstream of the human apoAI gene transcriptional start site $(+1)$, directs apoAI gene expression in hepatoma HepG2 and colon carcinoma Caco-2 cells but not in cervical carcinoma $\mathrm{HeLa}$ cells (9). First, we wanted to determine whether sequences in the apoCIII/apoAIV intergenic region could affect the transcrip- tional activity of the 2.5-kb DNA segment in either of these cell types. A 7-kb DNA segment spanning the intergenic region of the apoCIII and apoAIV genes and portions of their coding sequences (Fig. 1) was cloned adjacent to the $3^{\prime}$ end of the cat reporter gene in the -2500 AI.CAT construct that expresses cat under the control of the $2.5-\mathrm{kb}$ apoAI gene promoter segment. The resulting construct, -2500AI.CAT [CIII/AIV], the parental construct, -2500 AI.CAT, and constructs lacking the 2.5-kb apoAI gene promoter, -41AI.CAT and -41AI.CAT[CIII/AIV], (refer to Fig. 1) were used for transient expression assays by transfection into HepG2, Caco-2, and HeLa cells. The results show that compared with $-41 \mathrm{AI}$.CAT, -2500AI.CAT expressed high levels of CAT activity in HepG2 (24-fold) and Caco-2 (20-fold) but not in HeLa cells (Fig. 1), whereas -2500AI.CAT [CIII/AIV] expressed even greater levels of CAT activity in HepG2 (195-fold) and Caco-2 (71-fold) but not in HeLa cells (Fig. 1). In conclusion, the 7-kb apoCIII/ apoAIV intergenic region enhances expression of the apoAI gene both in liver and intestinal cells, and the $2.5-\mathrm{kb}$ apoAI promoter segment plays a fundamental role in mediating this transcriptional enhancement.

Different regions within the 2.5-kb ApoAI promoter mediate transcriptional enhancement by the 7-kb ApoCIII/ApoAIV element in liver and intestinal cells. We next determined whether separate apoAI promoter elements mediate transcriptional enhancement by the apoCIII/apoAIV intergenic region in HepG2 and Caco-2 cells. A series of apoAI/cat fusion constructs containing different regions of the $2.5-\mathrm{kb}$ apoAI gene promoter, either including or excluding the 7-kb apoCIII/apoAIV domain inserted at the $3^{\prime}$ end of the cat gene, were constructed and used for transient transfection assays in HepG2 and Caco-2 cells. The results show that the -595 to -41 apoAI promoter region was as effective as the $-2,500$ to -41 region in mediating apoAI gene transcriptional enhancement by the $7-\mathrm{kb}$ apoCIII/apoAIV element in both cell types (Figs. 1 and 2). In HepG2 cells, the -490 to $-41,-366$ to $-41,-256$ to -41 , and -192 to -41 regions showed $88 \%, 48 \%, 82 \%$, and $58 \%$, respectively, of the activity of the $-2,500$ to -41 region (Figs. 1 and 2), whereas in Caco-2 cells these regions showed 26\%, $15 \%, 29 \%$, and $18 \%$, of the activity of the $-2,500$ to -41 region, respectively (Figs. 1 and 2 ). The -595 to -192 region was the smallest region resulting in maximal transcriptional enhancement in Caco-2; however, this region was incapable of activating transcription in HepG2 cells ( see $-595[\Delta-192$ / -42]AI.CAT, Fig. 2). Therefore, separate and distinct cellspecific transcriptional elements in the -595 to -41 apoAI promoter region are required for maximal transcriptional enhancement of the apoAI gene by the apoCIII/apoAIV element in Caco-2 and HepG2 cells. The -595 to -192 element is required for this enhancement in Caco- 2 cells, whereas the -192 to -41 element is required for this enhancement in HepG2 cells. Thus, the effectiveness of transcriptional enhancement of the apoAI gene by the apoCIII/apoAIV domain was directly dependent on the basal activity of the associated apoAI promoter.

Different regions within the ApoCIII promoter enhance transcription of the ApoAI gene in liver and intestinal cells. We next determined whether the same or different regions within the 7-kb apoCIII/apoAIV domain determined the transcriptional enhancement of the apoAI gene in HepG2 and Caco-2 cells. A series of apoAI/cat fusion constructs, containing different portions of the 7-kb apoCIII/ApoAIV domain inserted $3^{\prime}$ of the 


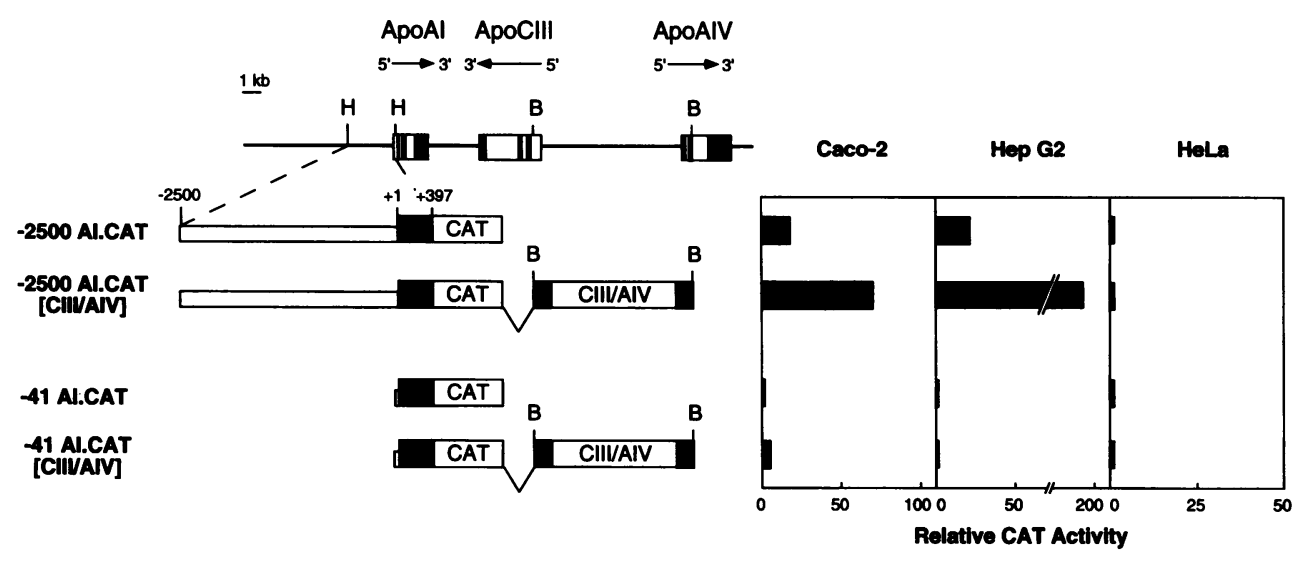

Figure 1. Transcriptional enhancement of the proximal apoAI promoter by a distal 7-kb apoCIIII apoAIV domain. The organization of the 5'-apoAI/apoCIII/apoAIV 3 ' gene cluster is indicated by a scaled illustration with the direction of transcription noted by the arrows. Introns and exons are shown by filled and open boxes, respectively. The apoAI gene promoter region between $-2,500$ and +397 (relative to the transcriptional start site, +1 ) was excised by digestion with HindIII $(H)$ and the apoCIIL/apoAIV intergenic re-

gion was excised by BamHI $(B)$ digestion and ligated into the $H$ and $B$ sites of the cat gene, respectively, to generate $-2,500$ AI.CAT [CIII/AIV]. Throughout this work, the numbers to the left of the construct schematic in the figure indicates the 5' position in the apoAI gene promoter region; the coordinates of deleted segments is indicated after the $\Delta$. The following constructs were transfected into Caco-2, HepG2, and HeLa cells: -2500 AI.CAT, which contains apoAI sequences from $-2,500$ to +397 fused to cat; -2500 AI.CAT [CIII/AIV], which additionally includes the 7-kb apoCIII/apoAIV element linked downstream of cat in -2500AI.CAT; -41AI.CAT contains the apoAI basal promoter sequences, -41 to +397 , fused to cat; and -41AI.CAT [CIII/AIV] includes the 7-kb apoCIII/apoAIV element downstream of cat in -41 AI.CAT. Equimolar plasmid amounts were used for the transfections. The ratio of CAT enzymatic activity to $\beta$-gal activity of a given construct is expressed relative to the CAT: $\beta$-gal ratio of -41AI.CAT and is shown in the bar graphs. These data represent the average experimental values from at least three independent experiments that differ by $\leq 5 \%$.

cat gene, were constructed and used for transient expression assays in HepG 2 and Caco- 2 cells. The results in Fig. 3 show that the construct containing the $-1,411$ to +783 apoCIII promoter/gene region was as effective as the entire 7-kb apoCIII/ apoAIV element in enhancing transcription of the apoAI gene in both of these cell types. Submapping of this element further showed that the -770 to -194 apoCIII promoter region showed $95 \%$ the activity of the 7-kb apoCIII/apoAIV domain in Caco2 cells and $61 \%$ the activity in HepG2 cells. The -92 to +783 and -168 to +783 apoCIII promoter/gene regions were not active in Caco-2 cells yet in HepG2 cells showed 54 and 57\% the activity of the 7-kb apoCIII/apoAIV domain, respectively. Similarly, the previously characterized apoCIII promoter nuclear factor binding sites $\mathrm{C} 3 \mathrm{P}(-92$ to -56$), \mathrm{NF} \kappa \mathrm{B}(-168$ to $-144)$, and $I(-770$ to -722$)(14,29,30)$ were not active in Caco-2 cells but showed 50,34 , and $100 \%$ the activity of the $7 \mathrm{~kb}$ apoCIII/apoAIV domain in HepG2 cells, respectively.

These observations indicate that different regions within the apoCIII promoter enhance transcription of the apoAI gene in liver and intestinal cells. Furthermore, these results suggest that enhancement of apoAI transcription in Caco-2 cells may depend on cooperative interactions of multiple sites within the apoCIII promoter, whereas enhancement in HepG2 cells may be mediated by multiple independently acting sites.

Caco-2 cell-specific nuclear factors bind to distinct sites within the -595 to -192 ApoAI promoter region. The -595 to -192 apoAI promoter region was assayed for nuclear factor binding sites by DNaseI protection assays using HepG2 and Caco-2 cell nuclear extracts. Two different DNA fragments spanning the -595 to -256 and -256 to -80 regions of the apoAI promoter were used as probes. The results show that Caco-2 nuclear extracts protect sites D ( -523 to -492$), \mathrm{E}$ $(-488$ to -467$), F(-450$ to -411$)$, and $G(-408$ to -393$)$, of which only sites $\mathrm{F}$ and $\mathrm{G}$ are protected by HepG2 nuclear extracts (Fig. $4 A$ ). Three additional sites, A $(-221$ to -193$)$, B $(-180$ to -147$)$, and C $(-142$ to -118$)$, were protected by both Caco-2 and HepG2 nuclear extracts (Fig. $4 B$ ).
Binding of nuclear proteins to these protected sites was assessed by labeling oligonucleotides corresponding to the sequences protected by sites D, E, F, and G and using them as probes for EMSAs. The results in Fig. $4 C$ show that nuclear factors from Caco-2 cells specifically bind to all of these oligos (lanes $1,5,9,13$ ), whereas proteins in HepG2 cell nuclear extracts did not bind to oligos $\mathrm{D}$ and $\mathrm{E}$ (lanes 4 and 8 ) but did bind to oligo $\mathrm{F}$ and weakly to oligo $\mathrm{G}$ (lanes 12 and 16). Thus, sequences in the apoAI promoter region protected in DNaseI assays bind nuclear factors in a specific fashion and sites $D$ and E appear to bind Caco-2 cell specific nuclear proteins. Taken together with the functional data presented in Fig. 2, these results suggest that occupation of the apoAI promoter sites D and E by enterocyte specific nuclear factors may play an important role in intestine specific expression of the apoAI gene.

$D N A$-protein binding site $A$ is required for expression of the apoAI gene in intestinal cells. We have previously shown that sequences between -214 and -192 in the apoAI gene promoter region [ site A (10)] are essential for maximal expression of the apoAI gene in HepG2 cells $(9,10)$; furthermore, this site is a NHRRE (11-13). The binding of factors to site A from Caco- 2 nuclear extracts was assessed by EMSA. Similar to our findings in HepG2 cells (10), the results in Fig. $5 \mathrm{~A}$ showed that Caco-2 nuclear factor(s) bind to oligo A and retard its electrophoretic mobility (lane 1 ). This binding is specific because inclusion of 100 -fold molar excess of unlabeled oligo $A$ in the binding reaction competed the retardation complex formation (lane 2), whereas inclusion of 100 -fold of unrelated oligo B did not influence retardation complex formation (lane 3). Importantly, 100-molar excess of oligo Amut in the binding reaction also did not influence retardation complex formation either (lane 4) nor did it bind Caco-2 nuclear extracts when it was used as a probe (data not shown).

We then determined the importance of site $\mathrm{A}$ in the function of the intestinal specific element in the apoAI promoter ( -595 to -192) and in mediating the transcriptional enhancement of the apoAI gene by the 7-Kb apoCIII/apoAIV domain. Using 


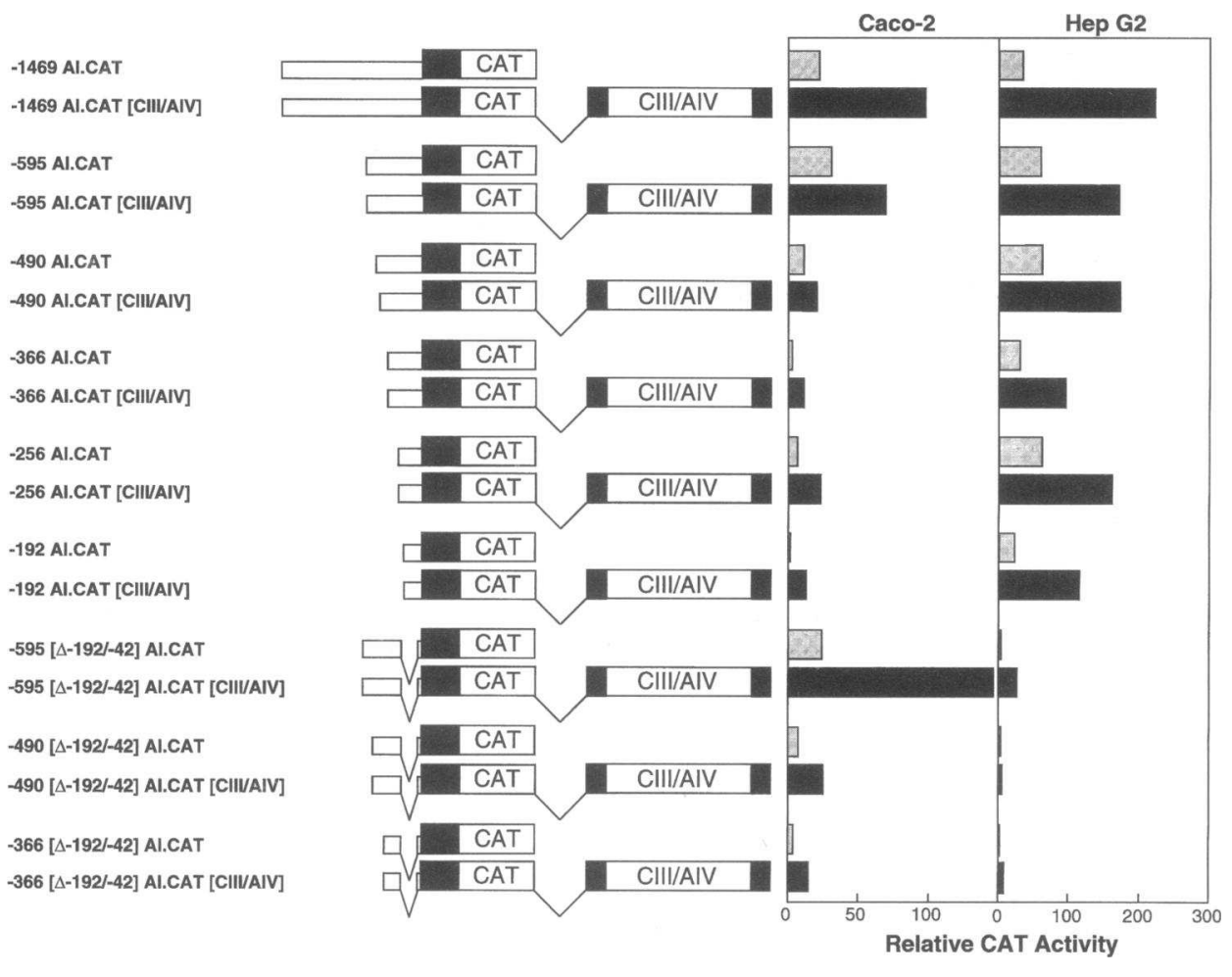

Figure 2. In Caco-2 and HepG2 cells, different subregions of the apoAI proximal promoter mediate the transcriptional enhancement by the 7-kb apoCIII/apoAIV domain. A series of apoAI gene promoter/cat gene fusion constructs were generated by restriction digestion of 2500AI.CAT. The 5' nucleotide coordinate in the promoter region is indicated to the left of the construct diagram. Constructs containing subsegments of the $2.5-\mathrm{kb}$ apoAI proximal promoter are fused to the cat gene are shown and are paired with a similar series of constructs that contain in addition the 7-kb apoCIII/ apoAIV domain ligated downstream of $c a t$. The bottom three pairs of constructs each contain a 150-bp deletion from -192 to -42 (denoted $\Delta-192$ / -42 ). These constructs were transfected into both Caco-2 and HepG2 cells. The CAT activities were determined and graphed as described in Fig. 1. These data represent the average experimental values from at least three independent experiments that differ by $\leq 5 \%$. site-directed mutagenesis and oligo Amut (see Methods for sequence), we constructed the plasmid -595AmAI.CAT containing a mutation of site $\mathrm{A}$ in situ. The transcriptional activity of this mutant was compared with the wild-type -595AmAI. CAT[CIII/AIV] and the transcriptional activity of -595AI. CAT [CIII/AIV] was compared with -595AmAI.CAT[CIII/ AIV] using transient transfection assays in Caco-2 and HepG2 cells (Fig. 5 B). In Caco-2 cells, -595AmAI.CAT expressed very low levels of CAT activity compared with -595AI.CAT, whereas in HepG2 cells the mutation in site A reduced CAT activity by only $30 \%$. When the apoCIII/apoAIV element is present, constructs with the site A mutant again expressed very low levels of CAT activity compared with the wild-type in Caco-2 cells, and the levels of expression from -595AmAI. CAT [CIII/AIV] were similar to the promoterless -41AI.CAT[CIII/AIV] in Fig. 1. In HepG2 cells, CAT activity of

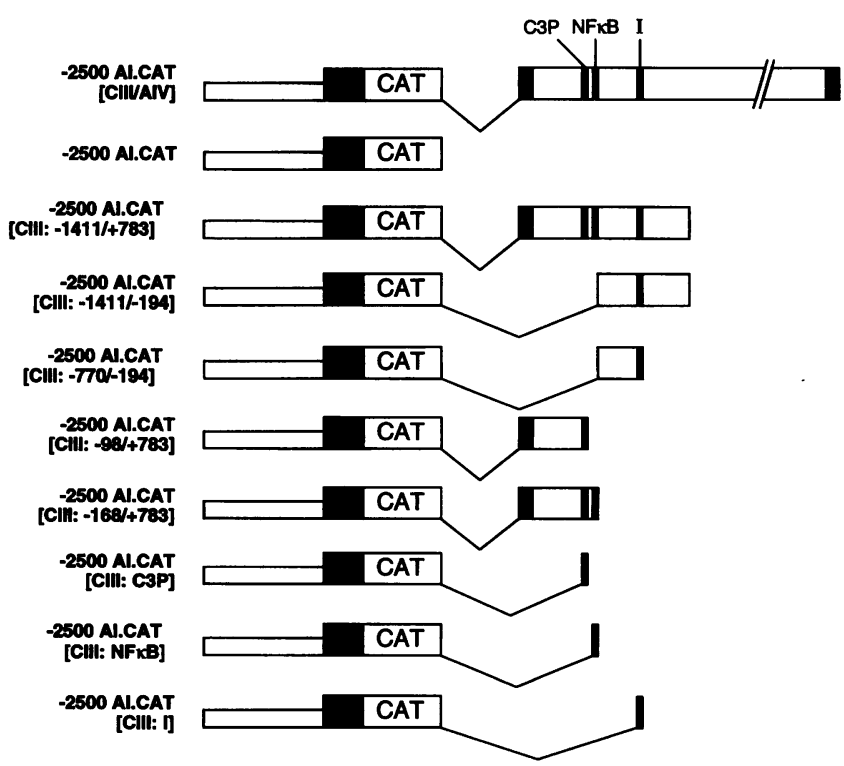

scriptional activation: C3P ( -92 to -56$)$, NFKB $(-168$ to -144$)$, and I $(-770$ to -722$)$. The CAT activities were determined and graphed as described in Fig. 1. These data represent the average experimental values from at least three independent experiments that differ by $\leq 5 \%$.
Figure 3. Potentiation of apoAI gene transcription by subfragments of apoCIII/apoAIV intergenic region. Constructs containing subregions of the 7-kb apoCIII/apoAIV intergenic region inserted downstream of the cat gene in the construct -2500 AI.CAT were transfected into HepG2 and Caco-2 cells. In all cases the $-2,500$ to +397 region of the apoAI gene promoter is fused upstream of $c a t$, whereas various subregions of the apoCIII gene promoter region are downstream of cat. The coordinates of the subfragments of the apoCIIII apoAIV intergenic region are indicated relative to the transcriptional start site of the apoCIII gene [CIII:+1]. Three previously described DNA-protein binding regions in the apoCIII promoter were tested as candidates for tran- 

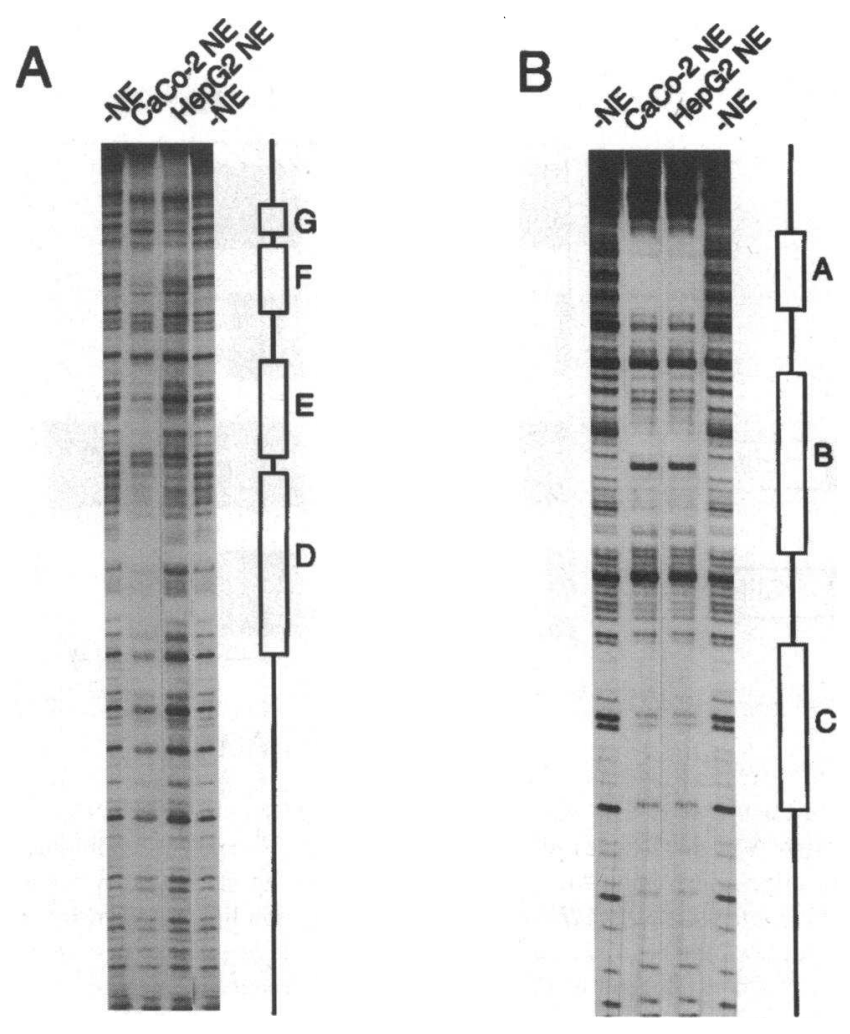

C
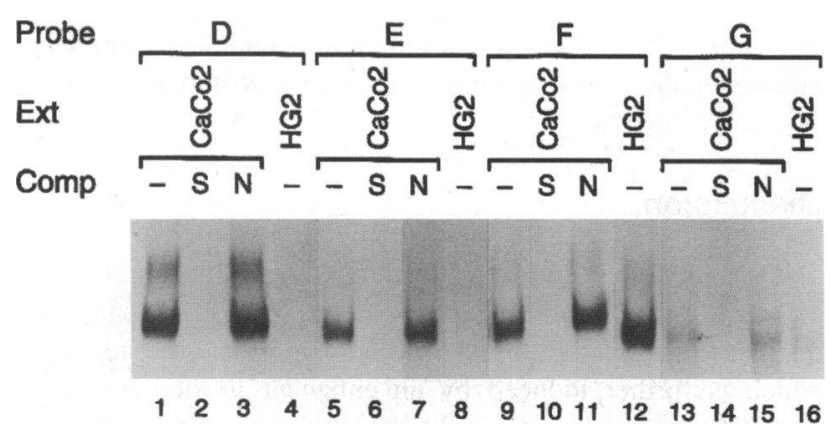

Figure 4. The apoAI proximal promoter contains multiple binding sites for intestinal cell nuclear proteins. Autoradiograms showing the DNaseI protection patterns of the $(A)-595$ to -256 and the $(B)-256$ to -80 regions of the apoAI promoter in the absence $(-N E)$ and presence of Caco-2 (Caco-2 NE) or HepG2 (HepG2 NE) cell nuclear extracts (NE). Protected regions are indicated as boxes along side the autoradiograms. Coordinates of the protected regions relative to the apoAI gene transcription start site are given in the text. $(C)$ Using the protected sequences, oligonucleotides for sites $D-G$ were labeled and used as probes in EMSA with Caco-2 and HepG2 (HG2) NE as indicated. $S$, specific competition with 100 -fold molar excess of an unlabeled oligo identical to the probe; $N S$, nonspecific competition with 100-fold molar excess of an unlabeled oligo unrelated to the probe.

-595AmAI.CAT[CIII/AIV] was reduced by $\sim 30 \%$ compared with the wild-type (-595AI.CAT[CIII/AIV]). These results suggest that binding of intestinal nuclear factors to site $\mathrm{A}$ is absolutely required for expression of apoAI in Caco- 2 cells, whereas in HepG2 cells this site is not necessary albeit for maximal expression, and intestinal factors binding to site A, perhaps nuclear hormone receptors, play a role in mediating the functional interaction between the apoAI promoter and the apoCIII/apoAIV element in intestinal cells.

Proteins that bind to site A in Caco-2 cells are antigenically similar to Ear3/COUP-TF, Arp-1, and HNF-4. As shown above, the -595 to -192 apoAI promoter region stimulates Caco-2 cell-specific expression of the apoAI gene in response to the distal apoCIII/apoAIV enhancer domain. This enhancement is strongly dependent on the apoAI promoter region containing the nuclear factor binding sites D, E, F, G, and A, and it is completely eliminated by mutation of site $A$.

Because site $A$ has been shown to bind several members of the nuclear hormone receptor superfamily such as Ear3/COUPTF, Arp-1, HNF-4, and RXR $\alpha$, as well as various RXR $\alpha / \mathrm{RAR}$ heterodimeric forms (11-13, and this work), we assayed whether these proteins contribute to the formation of retardation complexes between site A and Caco- 2 nuclear extracts. Electrophoretic mobility shift assays using Cos-1 cell produced Ear3/ COUP-TF, Arp-1, or HNF-4 showed that each of these proteins bind avidly and specifically to site A (Fig. 6, lanes 1, 4, 7, respectively) and with similar affinity (data not shown). Addition of an Ear3/COUP-TF specific antibody, which cross-reacts with $\operatorname{Arp}-1(14,36)$, to the EMSA incubation mixtures supershifts the retardation complexes formed with either Ear3/ COUP-TF (lane 2) or Arp-1 (lane 5) but not the complex formed with HNF-4 (lane 8). An HNF-4-specific antibody $(14,27)$ supershifts the complex formed with HNF-4 (lane 9) but not those formed with either Ear3/COUP-TF (lane 3) or Arp-1 (lane 6). Similar experiments using Caco-2 cell nuclear extracts revealed that most of the retardation complex is supershifted by a combination of both Ear3/COUP-TF and HNF-4 antibodies (lane 13). Antibodies against $\operatorname{RXR} \alpha, \operatorname{RXR} \beta, \operatorname{RAR} \alpha$, and $\operatorname{RAR} \beta$ were ineffective in supershifting the Caco-2-specific retardation complexes (data not shown). Therefore, most of the proteins in Caco-2 nuclear extracts that bind to site A are Ear3/COUP-TF, Arp-1, and HNF-4 or perhaps other antigenically related family members.

Overexpression of HNF-4 stimulates transcription of the ApoAI gene in Caco-2 cells but not in HepG2 cells. We next determined whether Arp-1 or HNF-4 binding to site A influences expression of the apoAI gene in Caco- 2 and HepG2 cells. Two previously described constructs were used for these experiments: [A]-41AI.CAT and [Am]-41AI.CAT, containing one copy of oligo A or one copy of oligo Amut, respectively, proximal to the apoAI gene basal promoter -41AI.CAT (13). Each of these constructs was used for transient expression assays in Caco-2 and HepG2 cells by cotransfection of either pMT2Arp or pMT2-HNF-4, two vectors expressing Arp-1 or HNF-4, respectively $(20)$. In both cell types the results showed that -41AI.CAT expressed very low levels of CAT activity regardless of whether Arp-1 or HNF-4 was also coexpressed in the same cells (Fig. 7). The construct [A]-41AI.CAT expressed higher levels of CAT activity, and Arp-1 coexpression eliminated this activity, whereas HNF-4 coexpression dramatically stimulated it. The results with the construct [Am]-41AI.CAT were analogous to those obtained with the construct $-41 \mathrm{AI}$. CAT. These results suggest that both HNF-4 and Arp-1 bind to site $A$ and interact with the basal transcription factors to stimulate and repress transcription, respectively, in both Caco-2 and HepG 2 cells. Further, in Caco- 2 cells, Arp-1 overexpression repressed the activity of the -595AI.CAT, whereas HNF-4 overexpression induced transcription from the -595 AI.CAT but not the -192AI.CAT constructs. The construct -595 AmAI. 


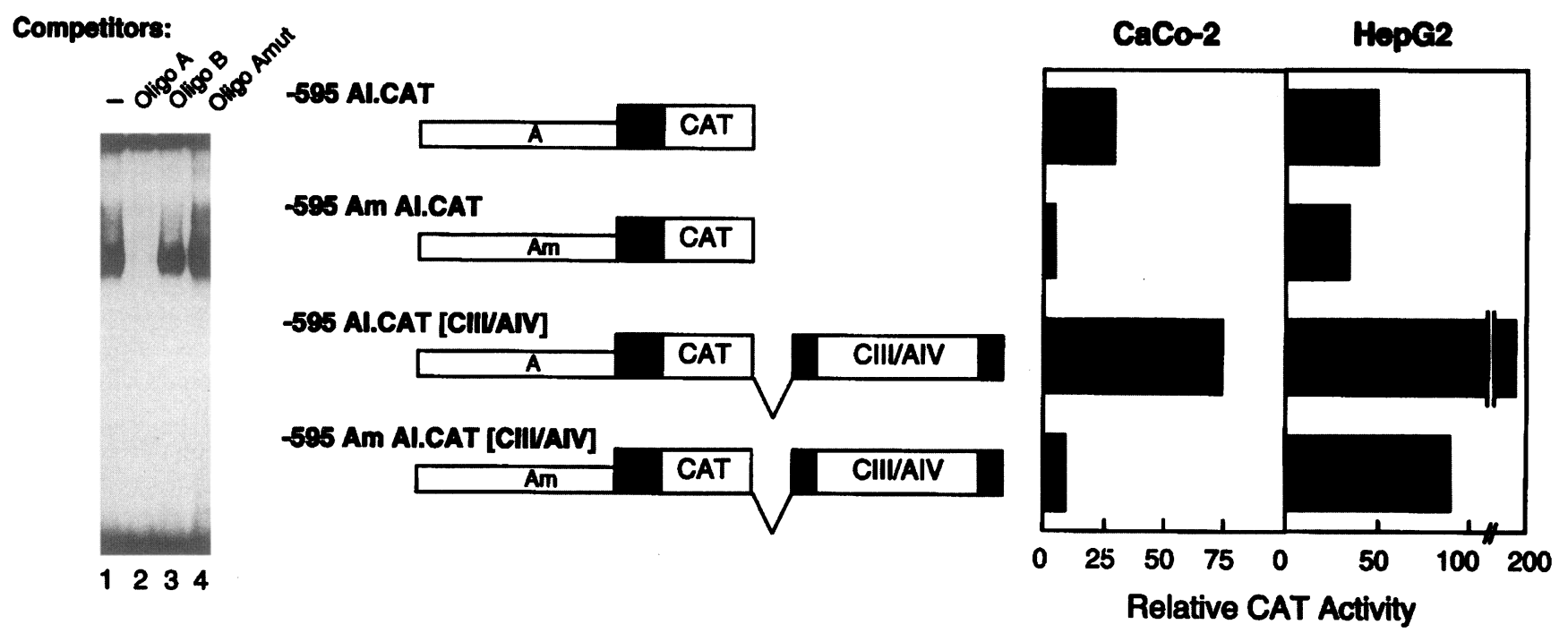

Figure 5. Site A in the apoAI proximal promoter is essential for expression in Caco-2 cells. (A) Autoradiograms from EMSA showing DNAprotein complexes formed after incubation of Caco-2 NE with radiolabeled oligo A in the absence of competitor (-) (lane 1$)$ and in the presence of 100-fold molar excess of competitor oligo A (lane 2), oligo B (lane 3), or oligo Amut (lane 4). (B) Constructs containing the apoAI promoter regions between -595 and +397 fusted to the cat gene without (top) and with (bottom) the apoCIII/apoAIV intergenic region ligated downstream of $c a t$ were transfected into Caco-2 and HepG2 cells. A, the wild-type of site A; Am, mutant of site A. The relative CAT activity values in extracts from these cells were determined and used for the bar graphs shown, as described in the legend to Fig. 1. These data represent the average experimental values from at least three independent experiments that differ by $\leq 5 \%$.

CAT showed lower levels of expression that was not significantly affected by the presence of Arp-1 or HNF-4. Importantly, in a similar series of experiments in HepG2 cells, coexpression of HNF-4 with these same constructs failed to induce expression above basal levels (Fig. 7). Similar results were obtained with constructs containing additional $5^{\prime}$ flanking sequences (e.g., -2500 AI.CAT), indicating that the response to Arp-1 and HNF-4 are dictated by the minimal promoter regions (data not shown). Thus, in Caco-2 cells, overexpression of HNF-4 augments the basal expression of the apoAI gene, an induction that requires site $\mathrm{A}$ and elements upstream of site $\mathrm{A}$; in HepG2 cells, however, over expression of HNF-4 in the context of the intact promoter region does not further stimulate expression over basal levels.

Finally, we determined whether HNF-4 could potentiate enhancement of apoAI gene transcription by the apoCIII/apoAIV element. In Caco-2 cells we observed that coexpression of HNF-4 markedly induced the activity of -595AI.CAT[CIII/ AIV] (Fig. 8). However, when site A is mutated, basal activity is reduced and is similar to -41AI.CAT [CIII/AIV]. Coexpression of HNF-4 resulted in an approximately fourfold induction of this low activity. The apoAI basal promoter, -41AI.CAT, was not induced by coexpression with HNF-4; however, -41AI.CAT[CIII/AIV] was induced approximately fivefold above its low basal activity. Maximal transactivation by HNF4 was only observed in the presence of both the -595 to -41 region upstream of the apoAI gene and the apoCIII/apoAIV element ( -595 AI.CAT [CIII/AIV]). In HepG2 cells coexpression of HNF-4 with these constructs did not result in induction of apoAI transcriptional activity (Fig. 8).

Taken together, the results in Fig. 8 indicate that transactivation of the apoAI gene by HNF-4 in intestinal cells depends both on functional synergy between HNF-4 bound to
apoAI gene site A with factors bound to sequences further upstream in the apoAI gene promoter and within the apoCIIII apoAIV element.

\section{Discussion}

The results in this study suggest that liver and intestinal specific expression of the apoAI gene is determined by separate and distinct tissue-specific apoAI promoter regions, the activity of which is further induced by an enhancer located within the apoCIII gene promoter, $\sim 5 \mathrm{~kb}$ downstream of the apoAI gene. The functional organization of this distal enhancer is different between liver and intestinal cells; enhancer activity in hepatic cells is mediated by multiple independently acting cis-acting elements, whereas enhancer activity in enterocytic cells appears to depend on functional cooperation between these cis-acting elements. Importantly, nuclear hormone receptors interact with an element essential for apoAI gene transcription in enterocytes. Moreover, HNF-4 transactivates the apoAI gene in enterocytes but not hepatocytes, suggesting an important role for this class of transcription factors in the regulation of enterocytic gene expression.

Previous studies indicated that expression of the apoAI gene in liver is controlled by a powerful hepatocyte-specific enhancer located between nucleotides -222 to -110 upstream of the apoAI gene transcriptional start site $(9,10)$. The function of this enhancer depends on synergistic interactions between transcription factors bound to three sites, sites A $(-214$ to -192$)$, B $(-169$ to -146$)$, and C $(-134$ to -110$)(10)$. Deletion mapping analysis of the apoAI promoter in the current study revealed that the promoter element from -192 to -41 is necessary and sufficient for stimulation of the apoAI gene by the downstream enhancer in hepatic HepG2 cells. This is consistent 


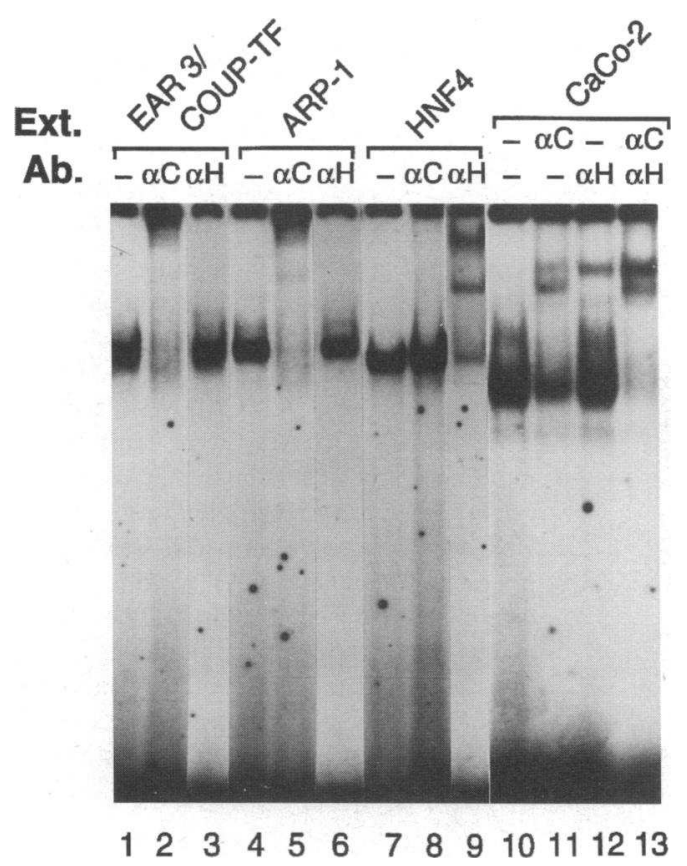

Figure 6. Caco-2 cell nuclear extracts contain factors antigenically related to Arp-1, COUP-TF, and HNF-4 that bind to site A. Autoradiograms from EMSA showing complexes formed by incubation of whole cell extracts (Ext.) from Cos-1 cells transiently transfected with either pMT2-Ear3/COUP-TF (lanes 1-3), pMT2-ARP-1 (lanes 4-6), or pMT2-HNF-4, (lanes 7-9) (see Methods) with radiolabeled oligo A either in the absence of $(-)$ or the presence of polyclonal antibodies $(A b$. ) to either Ear3/COUP-TF $(\alpha C)$ or to HNF-4 $(\alpha H)$. Caco-2 nuclear extract-specific complexes formed by incubation with radiolabeled oligo A either in the absence of $(-)$ or the presence of polyclonal antibodies $(A b$.) to either Ear3/COUP-TF $(\alpha C)$ or to HNF-4 $(\alpha H)$ (lanes 1013).

with the requirement of the -222 to -110 liver-specific enhancer for maximal expression of the apoAI gene in these cells (10). However, the similarity of the transcriptional activities of constructs containing the downstream enhancer and either the -256 to -41 or the -192 to -41 apoAI promoter elements is surprising because the -192 to -41 element lacks site A. Thus, the functional deficiency of the -192 to -41 apoAI promoter, because of its lack of site A, can be compensated for by the downstream enhancer. Similar observations have been made with the TTR and AFP genes, and it was suggested that redundancy of transcription factor binding sites in the promoter and enhancer facilitates enhancer-mediated rescue of trans-acting factor deficiencies in the promoter $(37,38)$. In this study, when using HepG 2 cells, apoAI promoter deficiencies, where sites B and $C(-192$ to -41$)$ are deleted, cannot be rescued by the distal downstream enhancer. Thus, it appears that occupation of sites $\mathrm{B}$ and $\mathrm{C}$ by transcription factors in hepatocytes commits expression of the apoAI gene in these cells and that subsequent occupation of site A or activation by the downstream enhancer can further maximize apoAI expression in liver. It is noteworthy that occupation of sites $\mathrm{B}$ and $\mathrm{C}$ by transcription factors in intestinal carcinoma (Caco-2) cells is neither necessary nor sufficient for activation of the apoAI gene by the downstream enhancer in these cells. Whether this is due to differences of factors that bind to sites B and C between these HepG2 and Caco- 2 cells or differences in the functional organization of the downstream enhancer between these two cell types (see below) is currently under investigation.

The -595 to -192 apoAI promoter element is necessary and sufficient for maximal stimulation of the apoAI gene by the downstream enhancer in Caco-2 but not HepG2 cells. Deletion of apoAI promoter sequences from -595 to -490 or mutagenesis of site A abolishes apoAI promoter responsiveness to the downstream enhancer in Caco-2 cells (Figs. 2 and 3 ). Furthermore, single or multiple copies of oligonucleotides corresponding to protein binding sites within the -595 to -192 region do not activate the apoAI basal promoter nor the SV40 early promoter in Caco-2 cells (our unpublished data). Therefore, it appears that synergy among the transcription factors that bind to the -595 to -192 region in enterocytes commits expression of the apoAI gene in these cells and that subsequent activation by the downstream enhancer maximizes apoAI expression in the intestine.

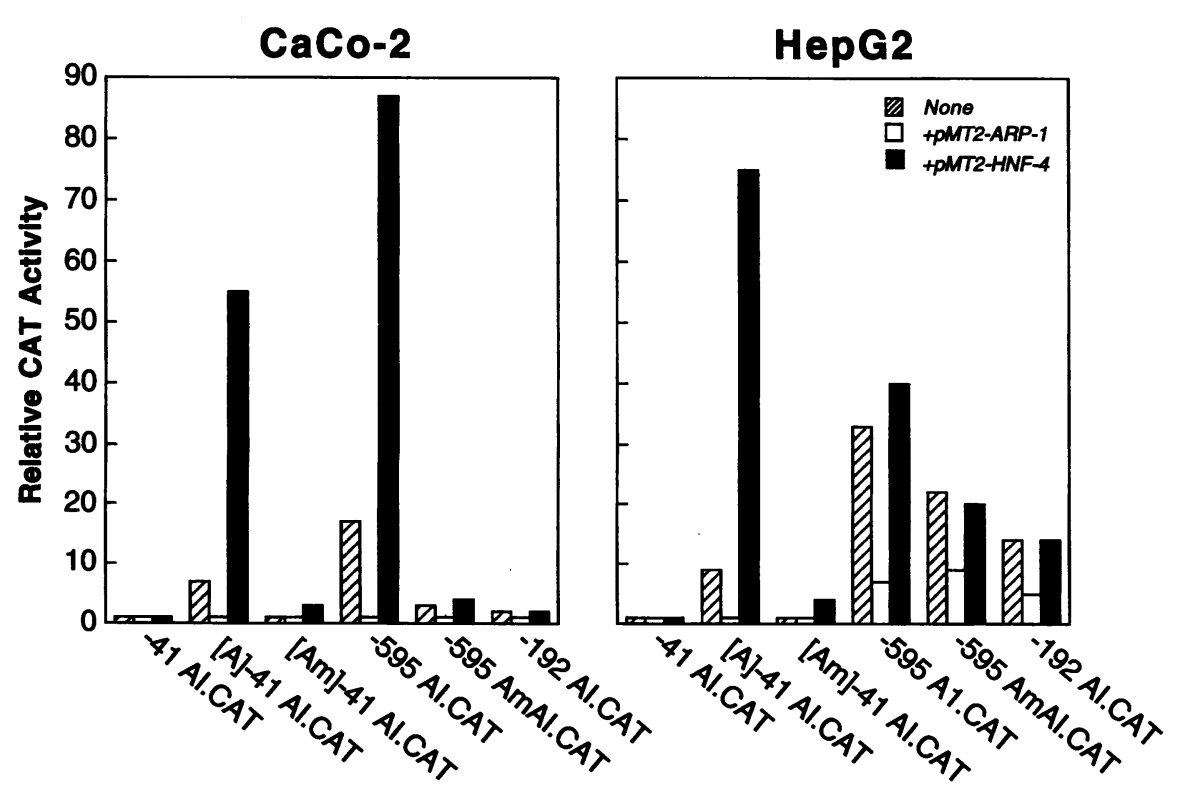

Figure 7. Effects of overexpression of HNF4 and ARP-1 on apoAI gene expression in intestinal (Caco-2) and hepatic (HepG2) cells. Constructs -41AI.CAT, [A]-41AI.CAT, and [Am] -41AI.CAT [ which contain one copy of oligo A, or one copy of mutated oligo A (oligo Amut) at position -41, respectively], in addition to -595AI.CAT, -595AmAI.CAT (containing a mutated site A), and -192AI.CAT were transfected into Caco-2 cells (left) or HepG2 cells (right) alone or together with either $5 \mu \mathrm{g}$ of the ARP-1 expression vector $p M T 2-A R P-1$ or 5 $\mu \mathrm{g}$ of the HNF-4 expression vector $P M T 2$ $H N F-4$, as indicated. The relative CAT activities were determined and used for the bar graphs shown, as described in the legend to Fig. 1. 


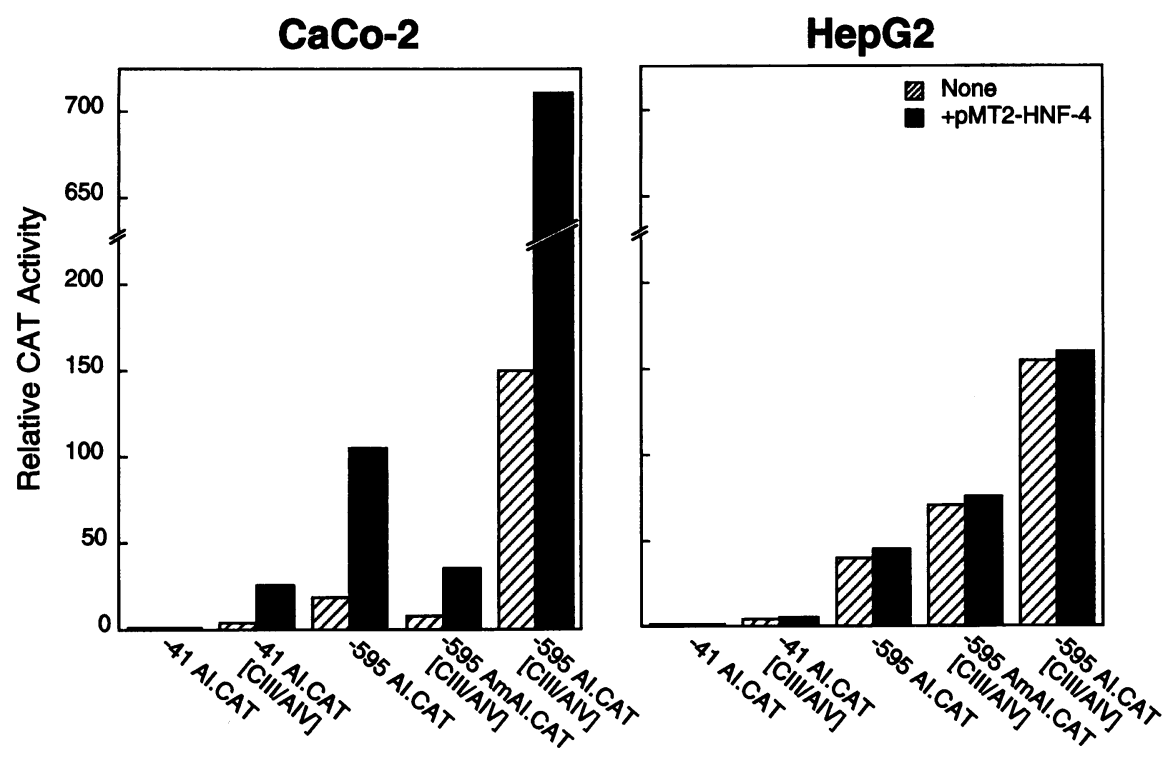

Figure 8. Effects of overexpression of HNF4 on apoAI gene expression in the presence of the apoCIII/apoAIV intergenic region in Caco-2 and HepG2 cells. The constructs -41 AI.CAT, -41AI.CAT[CIII/AIV], -595AI. CAT, -595AmAI.CAT[CIII/AIV], and -595AI.CAT[CIII/AIV] were transfected into Caco-2 cells (left) or HepG2 cells (right) alone or together with $5 \mu \mathrm{g}$ of the HNF-4 expression vector $p M T 2-H N F-4$, as indicated. The relative CAT activities were determined and used to construct the bar graphs shown, as described in the legend to Fig. 1. These data represent the average experimental values from at least three independent experiments that differ by $\leq 5 \%$.

The functional organization of the downstream enhancer was evaluated by deletion mapping analysis. All of the activity of this enhancer in both Caco-2 and HepG2 cells was localized to a DNA segment spanning the -1411 to +783 apoCIII promoter/gene region. However, further deletion mapping analysis revealed differences in the functional architecture of cis-acting elements within this enhancer between Caco-2 and HepG2 cells. Thus, although only the intact -770 to -194 apoCIII promoter region retained full enhancer activity in Caco- 2 cells, various subsegments of the $-1,411$ to +783 region retain substantial enhancer activity in HepG2 cells. In particular, an oligonucleotide spanning a previously defined protein binding site in the apoCIII promoter [site I, -770 to $-722(30)$ ] retained full enhancer activity in HepG 2 but not Caco- 2 cells. Additionally, site I has been shown to be essential for expression of the apoCIII gene in both Caco-2 and HepG2 cells (14), thus raising the possibility that site I and its cognate binding factor(s) may play a role in coordinating expression of both the apoAI and apoCIII genes.

The data from these transient transfection assays are in agreement with recent reports that intestinal expression of the human apoAI gene in transgenic mice is dependent on a 1.4$\mathrm{kb}$ DNA region located upstream of the apoCIII gene (26). We have further mapped this region to a 576-bp element residing between nucleotides -770 and -194 in the apoCIII promoter region. Transgenic mice lacking the apoCIII promoter region, however, do not express apoAI in their intestine, even in the presence of intestinal specific apoAI promoter sequences defined in this study. This discordant behavior between the transgenic mice and cell culture experiments has been described for locus control regions (LCRs). LCRs have been shown to behave as classical enhancers and have been implicated in an additional role of opening chromatin to allow access of transcription factors to the DNA and transcriptional machinery (39). This 576-bp region has properties similar to those of generalized enhancers; indeed, replacing this region with the SV40 promoter/enhancer in various apoAI promoter constructs results in qualitatively similar stimulation of transcription from the apoAI promoter in Caco-2 and HepG2 cells (our unpublished observations). The globin gene cluster LCR has been well described and is responsible for specifying site-of-integration independent, copy-number dependent, high level of expression of the gene in transgenic mice (40). These sequences, when studied in transient gene expression assays, have been shown to possess properties of enhancers capable of increasing the expression of the cis-linked gene by 300 -fold (41). Therefore, our data taken together with that from transgenic animals $(19,26)$ suggest the possibility that a LCR for the apoAIapoCIII-apoAIV gene cluster may be located upstream of the apoCIII gene.

Studies in transgenic mice have also suggested that a region upstream of the apoCIII gene is required for intestinal expression of this gene as well as the neighboring apoAIV gene. Thus, this region may contain an element responsible for controlling expression of the apoAI, apoCIII, and apoAIV genes. Evolutionary linkage of the apoAI, apoCIII, apoAIV genes for 300 million years suggests a selection advantage in maintenance of the tight linkage of the cluster. A similar observation has been made for the alpha-fetoprotein and albumin genes that are temporally coactivated, evolutionarily linked, and whose expression is dependent on a shared transcriptional element in their common intergenic region (42). Although the apoAI-apoCIII-apoAIV gene cluster does not undergo discrete developmental switches as do the globin genes or AFP and albumin, it is possible that different developmental patterns of these genes during embryogenesis and antenatally may be under the control of an LCR.

Site $\mathrm{A}$ in the apoAI promoter has been previously shown to bind various members of the steroid/thyroid hormone receptor superfamily such as $\operatorname{RXR} \alpha, \operatorname{RAR} \alpha, \operatorname{RAR} \beta, \operatorname{Arp}-1, \operatorname{Ear} 3 /$ COUP-TF, and HNF-4 (11-13). Polyclonal antibodies and EMSA analysis demonstrated that Caco-2 nuclear extracts contain HNF-4 and COUP-TF-like factors that bind to site A. Additionally, overexpression of Arp-1 represses expression of the apoAI gene in Caco- 2 cells, as has been previously shown in HepG2 cells (13). Arp-1 may act by displacing factors bound to site A because deletion of site A reduces the activity of the apoAI promoter and also eliminates its responsiveness to HNF4. Furthermore, overexpression of HNF-4 stimulates expression of the apoAI gene in Caco-2 but not HepG2 cells. The apparent 
lack of activation of the apoAI gene by HNF-4 overexpression in HepG2 cells is not due to lack of activity of the transfected HNF-4 in these cells because overexpression of HNF-4 in HepG 2 cells activates the apoCIII promoter (13) or the apoAI basal promoter linked to site A (Fig. 7). Therefore, in HepG2 cells, either site A within the apoAI promoter context is inaccessible to HNF-4 binding or transactivation by HNF-4 is dependent on additional uncharacterized factors required to transduce the HNF-4 signal to the basal promoter.

Maximal activation of the apoAI gene by HNF-4 in Caco2 cells requires site $A$ and the presence of sequences within the -595 to -366 intestinal cell specific apoAI promoter. This is very similar to the situation with the apoCIII gene where transactivation by HNF-4 is dependent on the presence of sequences further upstream from the HNF-4 binding site (site C3P, -67 to -87 ; see references 14 and 29 ). Importantly, in the presence of HNF-4, the activity of a construct containing both the apoAI intestinal-specific promoter and the downstream enhancer is at least sixfold greater than the sum of the activities of constructs containing either this promoter or this enhancer separately. Although HNF-4 may independently stimulate the apoAI basal promoter in the context of the apoCIII/apoAIV element (see Fig. 8, -41AI.CAT[CIII/AIV], our observations suggest that HNF-4 may promote functional communication between the apoAI enterocytic-specific promoter and the downstream enhancer. Since site A can be occupied by several members of the nuclear hormone receptor superfamily other than HNF-4 (see above), it is conceivable that these trans-regulators could also influence this promoter-enhancer functional communication and thereby modulate apoAI gene expression in the intestine.

In conclusion, expression of the apoAI gene in liver and intestine is controlled by separate and distinct tissue-specific apoAI promoter regions, the activity of which is further induced by a distal enhancer located within the nearby apoCIII promoter. HNF-4 appears to play an important role in the enterocytic but not hepatic expression of the apoAI gene. Elucidation of the mechanism by which HNF-4 and other nuclear hormone receptors regulate the apoAI gene and the characterization of intestinal cell-specific nuclear proteins that bind the apoAI gene promoter should provide insight into the molecular programs governing the developmental and physiological control of intestinal specific gene expression.

\section{Acknowledgments}

We thank Dr. M.-J. Tsai for providing the Ear3/COUP-TF antisera and Dr. F. M. Sladek and Dr. J. E. Darnell, Jr., for providing the HNF-4 antisera. We thank A. Lizonova, B. Scott, T. Salerno, and N. Papanicolaou for excellent technical assistance. We thank E. Flynn MacIntosh for artwork assistance, and D. Hernandez and L. Warren for typing the manuscript.

This research was supported by grants from the National Institutes of Health (HL-32032) and by American Cyanamid Co. During the course of these studies, G. S. Ginsburg was supported by an American Heart Association Parke Davis Clinician Scientist award (89-401) and S. K. Karathanasis was supported by an Established Investigator Award from the American Heart Association.

\section{References}

1. Wu, G. D., W. Wang, and P. G. Traber. 1992. Isolation and characterization of the human sucrase-isomaltase gene and demonstration of intestine-specific transcriptional elements. J. Biol. Chem. 267:7863-7870.
2. Sweetser, D. A., E. H. Birkenmeier, I. J. Klisak, S. Zollman, R. S. Sparkes, T. Mohandas, A. J. Lusis, and J. I. Gordon. 1987. The human and rodent intestinal fatty acid binding protein genes. A comparative analysis of their structure, expression, and linkage relationships. J. Biol. Chem. 262:16060-16071.

3. Elshourbagy, N. A., D. W. Walker, Y. K. Paik, M. S. Boguski, M. Freeman, J. I. Gordon, and J. M. Taylor. 1987. Structure and expression of the human apolipoprotein A-IV gene. J. Biol. Chem. 262:7973-7981.

4. Cohn, S. M., T. C. Simon, K. A. Roth, E. H. Birkenmeier, and J. I. Gordon. 1992. Use of transgenic mice to map cis-acting elements in the intestinal fatty acid binding protein gene (Fabpi) that control its cell lineage- specific and regional patterns of expression along the duodenal-colonic and crypt-villus axes of the gut epithelium. J. Cell Biol. 119:27-44.

5. Robine, S., C. Sahuquillo-Merino, D. Louvard, and E. Pringault. 1993. Regulatory sequences on the human villin gene trigger the expression of a reporter gene in a differentiating HT29 intestinal cell line. J. Biol. Chem. 268:1142611434.

6. Millan, J. L. 1987. Promoter structure of the human intestinal alkaline phosphatase gene. Nucleic Res. 15:10599.

7. Cognet, M., Y. C. Lone, S. Vaulont, A. Kahn, and J. Marie. 1987. Structure of the rat L-type pyruvate kinase gene. J. Mol. Biol. 196:11-25.

8. Rottman, J. N., and J. I. Gordon. 1993. Comparison of the patterns of expression of rat intestinal fatty acid binding protein/human growth hormone fusion genes in cultured intestinal epithelial cell lines and in the gut epithelium of transgenic mice. J. Biol. Chem. 268:11994-12002.

9. Sastry, K. N., U. Seedorf, and S. K. Karathanasis. 1988. Different cisacting DNA elements control expression of the human apolipoprotein AI gene in different cell types. Mol. Cell Biol. 8:605-614.

10. Widom, R. L., J. A. Ladias, S. Kouidou, and S. K. Karathanasis. 1991. Synergistic interactions between transcription factors control expression of the apolipoprotein AI gene in liver cells. Mol. Cell Biol. 11:677-687.

11. Ladias, J. A., and S. K. Karathanasis. 1991. Regulation of the apolipoprotein AI gene by ARP-1, a novel member of the steroid receptor superfamily. Science (Wash. DC). 251:561-565.

12. Rottman, J. N., R. L. Widom, B. Nadal-Ginard, V. Mahdavi, and S. K. Karathanasis. 1991. A retinoic acid-responsive element in the apolipoprotein AI gene distinguishes between two different retinoic acid response pathways. Mol. Cell. Biol. 11:3814-3820.

13. Widom, R. L., M. Rhee, and S. K. Karathanasis. 1992. Repression by ARP-1 sensitizes apolipoprotein AI gene responsiveness to RXR alpha and retinoic acid. Mol. Cell. Biol. 12:3380-3389.

14. Mietus-Snyder, M., F. M. Sladek, G. S. Ginsburg, C. F. Kuo, J. A Ladias, J. E. Darnell, Jr., and S. K. Karathanasis. 1992. Antagonism between apolipoprotein AI regulatory protein 1, Ear3/COUP- TF, and hepatocyte nuclear factor 4 modulates apolipoprotein CIII gene expression in liver and intestinal cells. Mol. Cell Biol. 12:1708-1718.

15. Karathanasis, S. K. 1992. Lipoprotein metabolism: high density lipoprotein. Monogr. Hum. Genet. 14:140-171.

16. Chao, Y. S., X. H. Ding, P. H. Dai, T. J. Wu, T. C. Pan, Q. L. Hao, and T. T. Yamin. 1988. Identification of an enhancer-like element in the $5^{\prime}$ flanking region of the rat apolipoprotein A-I gene. Nucleic Acids Res. 16:7061-7070.

17. Higuchi, K., S. W. Law, J. M. Hoeg, U. K. Schumacher, N. Meglin, and H. B. Brewer, Jr. 1988. Tissue-specific expression of apolipoprotein A-I (ApoA-I) is regulated by the 5'-flanking region of the human ApoA-I gene. $J$. Biol. Chem. 263:18530-18536.

18. Papazafiri, P., K. Ogami, D. P. Ramji, A. Nicosia, P. Monaci, C. Cladaras, and V. I. Zannis. 1991. Promoter elements and factors involved in hepatic transcription of the human ApoA-I gene positive and negative regulators bind to overlapping sites. J. Biol. Chem. 266:5790-5797.

19. Walsh, A., Y. Ito, and J. L. Breslow. 1989. High levels of human apolipoprotein A-I in transgenic mice result in increased plasma levels of small high density lipoprotein (HDL) particles comparable to human HDL3. J. Biol. Chem. 264:6488-6494.

20. Rubin, E. M., B. Y. Ishida, S. M. Clift, and R. M. Krauss. 1991. Expression of human apolipoprotein A-I in transgenic mice results in reduced plasma levels of murine apolipoprotein A-I and the appearance of two new high density lipoprotein size subclasses. Proc. Natl. Acad. Sci. USA 88:434-438.

21. Karathanasis, S. K. 1985. Apolipoprotein multigene family: tandem organization of human apolipoprotein AI, CIII, and AIV genes. Proc. Natl. Acad. Sci. USA. 82:6374-6378.

22. Haddad, I. A., J. M. Ordovas, T. Fitzpatrick, and S. K. Karathanasis. 1986. Linkage, evolution, and expression of the rat apolipoprotein A-I, C-III, and A-IV genes. J. Biol. Chem. 261:13268-13277.

23. Lamon-Fava, S., R. Sastry, S. Ferrari, T. B. Rajavashisth, A. J. Lusis, and S. K. Karathanasis. 1992. Evolutionary distinct mechanisms regulate apolipoprotein A-I gene expression: differences between avian and mammalian apoA-I gene transcription control regions. J. Lipid Res. 33:831-842.

24. Lauer, S. J., W. S. Simonet, N. Bucay, H. V. de Silva, and J. M. Taylor. 1991. Tissue specific expression of the human apolipoprotein AIV gene in transgenic mice. Circulation. 84:II-17. (Abstr.)

25. O’Connell, A., A. Walsh, N. Azrolan, and J. L. Breslow. 1990. Intestinal 
expression of human apoAI and apoCIII in transgenic mice. Circulation. 82:III433. (Abstr.)

26. Walsh, A., N. Azrolan, K. Wang, A. Marcigliano, A. O'Connell, and J. L. Breslow. 1993. Intestinal expression of the human apoA-I gene in transgenic mice is controlled by a DNA region 3 ' to the gene in the promoter of the adjacent convergently transcribed apoC-III gene. J. Lipid Res. 34:617-623.

27. Sladek, F. M., W. M. Zhong, E. Lai, and J. E. Darnell, Jr. 1990. Liverenriched transcription factor HNF-4 is a novel member of the steroid hormone receptor superfamily. Genes \& Dev. 4:2353-2365.

28. Maniatis, T., E. F. Fritsch, and J. Sambrook. 1989. Molecular Cloning: A Laboratory Manual. 2nd ed. Cold Spring Harbor Laboratory Press, Cold Spring Harbor, NY.

29. Leff, T., K. Reue, A. Melian, H. Culver, and J. L. Breslow. 1989. A regulatory element in the apoCIII promoter that directs hepatic specific transcription binds to proteins in expressing and non-expressing cell types. J. Biol. Chem. 264:16132-16137.

30. Ogami, K., M. Hadzopoulou-Cladaras, C. Cladaras, and V. I. Zannis. 1990. Promoter elements and factors required for hepatic and intestinal transcription of the human ApoCIII gene. J. Biol. Chem. 265:9808-9815.

31. Graham, F. L., and A. J. Eb. 1973. A new technique for the assay of infectivity of human adenovirus 5 DNA. Virology. 52:456-467.

32. Edlund, T., M. D. Walker, P. J. Barr, and W. J. Rutter. 1985. Cell-specific expression of the rat insulin gene: evidence for role of two distinct 5 ' flanking elements. Science (Wash. DC). 230:912-916.

33. Dignam, J. D., R. M. Lebovitz, and R. G. Roeder. 1983. Accurate transcription initiation by RNA polymerase II in a soluble extract from isolated mammalian nuclei. Nucleic Acids Res. 11:1475-1489.
34. Lowry, O. H., N. J. Rosebrough, A. L. Farr, and R. J. Randall. 1951. Protein measurement with the Folin phenol reagent. J. Biol. Chem. 193:265-275.

35. Kaufman, R. J. 1990. Vectors used for expression in mammalian cells. Methods Enzymol. 185:487-511.

36. Cooney, A. J., X. Leng, S. Y. Tsai, B. W. O’Malley, and M. J. Tsai. 1993. Multiple mechanisms of chicken ovalbumin upstream promoter transcription factor-dependent repression of transactivation by the vitamin $\mathrm{D}$, thyroid hormone, and retinoic acid receptors. J. Biol. Chem. 268:4152-4160.

37. Costa, R. H., and D. R. Grayson. 1991. Site-directed mutagenesis of hepatocyte nuclear factor (HNF) binding sites in the mouse transthyretin (TTR) promoter reveal synergistic interactions with its enhancer region. Nucleic Acids Res. 19:4139-4145.

38. Zhang, D. E., X. Ge, J. P. Rabek, and J. Papaconstantinou. 1991. Functional analysis of the trans-acting factor binding sites of the mouse alpha-fetoprotein proximal promoter by site-directed mutagenesis. J. Biol. Chem. 266:2117921185.

39. Grosveld, F., G. Blom van Assendelft, D. R. Greaves, and G. Kolleas. 1987. Position-independent, high-level expression of the human beta-globin gene in transgenic mice. Cell. 51:975-985.

40. Townes, T. M., and R. R. Behringer. 1990. Human globin locus activation region (LAR): role in temporal control. Trends Genet. 6:219-223.

41. Tuan, D. Y. H., W. B. Solomon, I. M. London, and D. P. Lee. 1989. An erythroid-specific, developmental-stage-independent enhancer far upstream of the human " $\beta$-like globin" genes. Proc. Natl. Acad. Sci. USA. 86:2554-2558.

42. Hammer, R. E., R. Krumlauf, S. A. Camper, R. L. Brinster, and S. M. Tilghman. 1987. Diversity of alpha-fetoprotein gene expression in mice is generated by a combination of separate enhancer elements. Science (Wash. DC). 235:53-58. 